\title{
APLP1 as a cerebrospinal fluid biomarker for $\gamma$-secretase modulator treatment
}

\author{
Simon Sjödin ${ }^{1 *}$, Kerstin K. A. Andersson ${ }^{1}$, Marc Mercken² ${ }^{2}$ Henrik Zetterberg ${ }^{1,3}$, Herman Borghys ${ }^{2}$, Kaj Blennow ${ }^{1}$ \\ and Erik Portelius ${ }^{1}$
}

\begin{abstract}
Introduction: Alzheimer's disease brains are characterized by extracellular plaques containing the aggregated amyloid $\beta_{42}\left(A \beta_{42}\right)$ peptide and intraneuronal tangles containing hyperphosphorylated tau. $A \beta_{42}$ is produced by sequential processing of the amyloid precursor protein (APP) by $\beta$-secretase followed by $\gamma$-secretase. Substantial efforts have been put into developing pharmaceuticals preventing the production or increasing the clearance of $A \beta_{42}$. However, treatments inhibiting $\gamma$-secretase have proven disappointing due to off-target effects. To circumvent these effects, $\gamma$-secretase modulators (GSMs) have been developed, which rather than inhibiting $\gamma$-secretase shift its preference into producing less aggregation-prone shorter $A \beta$ peptides. Belonging to the same family of proteins as APP, amyloid-like protein 1 (APLP1) is also a substrate for $\gamma$-secretase. Herein we investigated whether the GSM E2012 affects APLP1 processing in the central nervous system by measuring APLP1 peptide levels in cerebrospinal fluid (CSF) before and after E2012 treatment in dogs.

Methods: An in-house monoclonal APLP1 antibody, AP1, was produced and utilized for immunopurification of APLP1 from human and dog CSF in a hybrid immuno-affinity mass spectrometric method. Seven dogs received a single dose of 20 or $80 \mathrm{mg} / \mathrm{kg}$ of E2012 in a randomized cross-over design and CSF was collected prior to and 4,8 and 24 hours after dosing.
\end{abstract}

Results: We have identified 14 CSF APLP1 peptides in humans and 12 CSF APLP1 peptides in dogs. Of these, seven were reproducibly detectable in dogs who received E2012. We found a dose-dependent relative increase of the CSF peptides APLP1 $1317,1 \beta 18$ and $1 \beta 28$ accompanied with a decrease of $1 \beta 25$ and $1 \beta 27$ in response to E2012 treatment. All peptides reverted to baseline over the time of sample collection.

Conclusion: We show an in vivo effect of the GSM E2012 on the processing of APLP1 which is measurable in CSF. These data suggest that APLP1 peptides may be used as biomarkers to monitor drug effects of GSMs on $\gamma$-secretase processing in clinical trials. However, this requires further investigation in larger cohorts, including studies in man.

\section{Introduction}

Alzheimer's disease (AD) is a progressive neurodegenerative disorder and the most prevalent form of dementia [1]. It is characterized by extracellular plaques, containing aggregated amyloid- $\beta(A \beta)$ peptides [2], and intraneuronal tangles consisting of hyperphosphorylated tau [3]. In the amyloid cascade hypothesis, it is postulated that there is an imbalance in the production and/or clearance of $A \beta$

\footnotetext{
* Correspondence: simon.sjodin@neuro.gu.se

'Institute of Neuroscience and Physiology, Department of Psychiatry and Neurochemistry, The Sahlgrenska Academy at the University of Gothenburg, Sahlgrenska University Hospital, Mölndal S-431 80, Sweden

Full list of author information is available at the end of the article
}

which is believed to cause a series of events including microglial activation, oxidative stress, neuronal dysfunction, formation of tangles and inevitable neurodegeneration [4]. For these reasons, targeting the production of the aggregation prone and potentially toxic 42 amino acid residue-long variant of $A \beta\left(A \beta_{42}\right)$ has been subject to extensive research with the aim of developing disease modifying compounds that inhibits or modulates the enzymes responsible for the formation of $A \beta$ (see elaborating reviews elsewhere [5-7]).

The amyloid precursor protein (APP) is subjected to proteolytic processing by three secretases: $\alpha$-secretase, $\beta$-secretase and $\gamma$-secretase. The proteolytic activity of 
$\alpha$-secretase is likely attributed to the protein disintegrin and metalloproteinase domain-containing protein 10 (ADAM10) [8]; $\beta$-secretase has been identified as $\beta$-site APP-cleaving enzyme (BACE) [9]; whereas $\gamma$-secretase is a multisubunit protein complex consisting of nicastrin (NCSTN), anterior pharynx-defective 1 (APH-1), presenilin enhancer 2 (PEN2) and the $\mathrm{N}$ - and C-terminal fragments of presenilin 1 or 2 (PS1 or PS2) [10]. A $\beta_{42}$ is produced through the amyloidogenic pathway where APP is cleaved by $\beta$-secretase [9] and subsequently by $\gamma$ secretase [11]. Alternatively $A \beta_{42}$ production is prevented in the non-amyloidogenic pathway where $\alpha$-secretase rather than $\beta$-secretase cleaves APP within the A $\beta$ sequence generating shorter $A \beta$ peptides [12].

Secretases are an appealing target to alter the metabolism of $A \beta$. However, recent clinical trials where $A D$ patients were treated with $\gamma$-secretase inhibitors failed to reach their primary clinical endpoints; the cognitive decline was even worse in the treatment arm than in placebo $[13,14]$. A diverse array of transmembrane proteins have been identified as $\gamma$-secretase substrates [15], including Notch [16, 17], and the problems associated with $\gamma$ secretase inhibitor treatment may be explained by the physiological functions of these substrates [15].

To overcome the possible negative effects of inhibiting $\gamma$-secretase, $\gamma$-secretase modulators (GSMs) have been developed to shift the production from the amyloidogenic $\mathrm{A} \beta_{42}$ to less aggregation-prone peptides (e.g., $\mathrm{A} \beta_{38}$ ) without affecting the release of the intracellular domains of APP and other $\gamma$-secretase substrates such as Notch1, cadherins, Erb4 and EphB2 [18]. Thus, these compounds modulate the cleavage pattern of $A \beta$ without inhibiting, for example, Notch signaling. The effect of GSMs on APP processing has previously been shown to be measurable in vivo in cerebrospinal fluid (CSF) from, for example, monkeys [19] and guinea pigs [20], where the level of $A \beta_{42}$ decreased and $A \beta_{37}$ or $A \beta_{38}$ increased $[19,20]$. In agreement with these studies, we recently showed that dogs treated with the GSM E2012 displayed a distinct shift in the CSF $A \beta$ peptide pattern with decreased levels of $A \beta_{42}$ as well as $A \beta_{39}$ and $A \beta_{40}$ accompanied with increased levels of $A \beta_{37}$ [21]. The effects of different GSMs on $A \beta$ production have been summarized in a review by Crump et al. [22].

Amyloid-like protein 1 (APLP1) and APP share, to a large extent, similar structural domains and are both suggested to be involved in neurite outgrowth, cell adhesion and neuronal migration [23]. APLP1 and APP are also known to form heterodimers with possible implications in cell adhesion and synaptogenesis [24, 25]. APLP1 has been suggested to be processed by the same enzymatic activities as APP including $\gamma$-secretase and $\alpha$-secretase, generating a p3-like peptide called ALP-1 [24, 26], similar to the putative $\mathrm{p} 3$ fragment identified as a possible proteolytic product from APP [27]. While it is established that $\gamma$ secretase is responsible for the $\mathrm{C}$-terminal processing of APLP1 [28-30], the secretase cleaving at the Nterminus has been suggested to be either $\alpha-[26]$ or $\beta$ secretase $[28,31]$.

Recently, it was shown that APLP is processed into short $A \beta$-like peptides (APLP1 $\beta 25,1 \beta 27$ and 1 $1 \beta 28$ ) [28] and that the concentrations of CSF APLP1 $\beta 25$ and $1 \beta 27$ were decreased while the concentration of CSF APLP1 $\beta 28$ was unchanged in four different PS1 mutation carriers [32] leading to an increased APLP1 $\beta 28$ to total APLP1 $\beta$ ratio [28]. In addition, cells treated with the $A \beta_{42}$ raising GSM S2474, or cells harboring certain PS1 mutations were also found to have an increased APLP1 328 to total APLP1 $\beta$ ratio and it was suggested that this ratio may reflect the $A \beta_{42}$ production in the brain [28]. However, how the S2474 treatment or PS1 mutations affected the APLP1 128 concentrations were not reported. Whether APLP1 peptides can be used as CSF AD biomarkers reflecting $A \beta_{42}$ production needs to be investigated in large clinical studies, including early clinical stage of $\mathrm{AD}, \mathrm{AD}$ dementia and control subjects, in which other CSF and imaging biomarkers are included.

In order to characterize APLP1 in CSF, we developed a monoclonal antibody directed against APLP1. We then used hybrid immuno-affinity-based enrichment of CSF APLP1 peptides from dogs followed by mass spectrometry (MS) analysis. In the present study we tested the hypothesis that peptides derived from APLP1 can be used as in vivo biomarkers reflecting treatment with the second generation GSM E2012.

\section{Methods}

\section{Chemicals}

The $\gamma$-secretase modulator E2012 (cas no. 870843-42-8, (3E)-1-[(1S)-1-(4-fluorophenyl)ethyl]-3-[[3-methoxy-4(4-methyl-1H-imidazol-1-yl)phenyl]methylene]-2-piperidinone) was synthesized according to the described procedure [33].

\section{Experimental animals}

Beagle dogs were given a single oral dose of 20 and $80 \mathrm{mg} / \mathrm{kg}$ E2012 with a dosing interval of at least 1 week. The animals were exposed in a randomized cross-over study as previously described [21]. The animals (seven males, age 6- 8 years) received the compound with a liquid meal between 7 and 8 am and $1 \mathrm{ml} \mathrm{CSF}$ was collected prior to the meal and 4, 8 and 24 hours after dosing. The meal consisted of $120 \mathrm{ml}$ concentrated liquid (Convalescence support, one satchel dissolved in $112.5 \mathrm{ml}$ warm water; Crown Pet Foods Ltd., Castle Cary, UK) to which the compounds had been added directly before feeding. CSF was collected from awake animals from the lateral ventricle via a cannula. The CSF was collected into 
polypropylene tubes, immediately placed on dry ice and stored at $-80^{\circ} \mathrm{C}$ until analysis. The method for implanting and collecting CSF via the cannula in dogs has been described elsewhere [34]. In brief, a hole was drilled in the cranium of the dogs into which the cannula was screwed. The cannula was positioned at the following coordinates: $38-40 \mathrm{~mm}$ rostral to the occipital protuberance and $8 \mathrm{~mm}$ lateral to the center of the sagittal crest. The study was conducted according to protocol 2009-252-SD MECHPHA, approved by the Ethical Committee on Laboratory Animal Testing (Ethische Commissie Dierproeven, Johnson \& Johnson Pharmaceutical Research and Development, Beerse, Belgium).

\section{Generation of anti-APLP1 antibody}

A monoclonal antibody against APLP1, named AP1, was generated by immunization of 8-week-old Balb/c mice with the KLH-conjugated peptide APLP1 (amino acid 568-579, [UniProtKB:P51693]; Caslo ApS, Lyngby, Denmark) in complete Freund's adjuvant (Sigma-Aldrich Co., St Louis, MO, USA). After three dosages (approximately $75 \mu \mathrm{g} /$ mouse), the spleen was removed and B cells were fused with the myeloma cell line SP2/0 following standard procedure. Approximately 10 days after fusion, cell media were screened for APLP1 antibodies using APLP1 full length and neurogranin (Caslo ApS) as a negative control. Clones which reacted with the APLP1 protein were further grown, subcloned and subsequently frozen in liquid nitrogen. The isotype was determined using a commercially available kit (Pierce Rapid Isotyping Kit-Mouse; Thermo Fisher Scientific Inc., Waltham, MA, USA). Finally, antibodies were purified using a protein G column (GE Healthcare Bio-Sciences AB, Uppsala, Sweden).

\section{Immuno-affinity mass spectrometry}

CSF collected prior to dosing and 4, 8 and 24 hours after dosing with 20 or $80 \mathrm{mg} / \mathrm{kg}$ E2012 was analyzed by hybrid immuno-affinity MS as described previously with some modifications [21]. In brief, $4 \mu \mathrm{g}$ of the in-house developed mouse monoclonal anti-APLP1 antibody AP1 was incubated with $25 \mu \mathrm{l}$ magnetic beads conjugated to sheep anti-mouse IgG (Dynabeads M280, Invitrogen, Thermo Fisher Scientific Inc.). Beads with the AP1 antibody complex were then washed in phosphate-buffered saline and added to $600 \mu \mathrm{l} \mathrm{CSF}$ containing $0.0025 \%$ Tween, to a total volume of $625 \mu \mathrm{l}$. CSF with added beads was incubated over night at $+8{ }^{\circ} \mathrm{C}$ on a rocking platform. Elution of APLP1 was performed in a five-step procedure using a KingFisher $\mathrm{mL}$ Magnetic Particle Processors system (Thermo Fisher Scientific Inc.). The eluate was dried and redissolved in $5 \mu \mathrm{l} 0.1 \%$ formic acid in $20 \%$ acetonitrile. The sample in solution was mixed in a 2:1 ratio with a sample matrix containing $15 \mathrm{~g} / \mathrm{l}$ alpha-cyano-4-hydroxycinnamic acid and $0.1 \%$ trifluoroacetic acid in acetonitrile and spotted on an MTP 384 target plate polished steel TF (Bruker Daltonics $\mathrm{GmbH}$, Bremen, Germany) with a seed layer containing $20 \mathrm{~g} / \mathrm{l}$ alpha-cyano-4-hydroxycinnamic acid in $10 \%$ methanol and $90 \%$ acetone. The samples were analyzed as duplicates by matrix-assisted laser desorption ionization time-of-flight/time-of-flight (MALDI-TOF/TOF) using an UltrafleXtreme (Bruker Daltonics $\mathrm{GmbH}$ ) mass spectrometer operating at positive reflector mode. The sample spectra acquired were processed using flexAnalysis v3.3 (Bruker Daltonics $\mathrm{GmbH}$ ) by performing baseline subtraction, smoothening and internal calibration based on the theoretical monoisotopic masses of APLP1 fragments $1 \beta 17(1615.79 \mathrm{~m} / \mathrm{z}), 1 \beta 18(1728.88 \mathrm{~m} / \mathrm{z}), 1 \beta 22(2143.11 \mathrm{~m} /$ $z), 1 \beta 25(2328.19 \mathrm{~m} / \mathrm{z}), 1 \beta 27(2472.24 \mathrm{~m} / \mathrm{z})$ and $1 \beta 28$ $(2585.32 \mathrm{~m} / z)$. Exported peak lists were subjected to processing by an in-house MATLAB (Mathworks Inc., Natick, Massachusetts, USA) program which, in short, relative to the monoisotopic peak, integrated the peak areas within the limits of -2 to $+5 \mathrm{~m} / z$. Following this, the integrated peak areas in each specific spectrum were normalized as the percentage of the total area of all peaks measured. Duplicate measurements were averaged and then a fold-change was calculated for samples acquired at 4,8 and 24 hours against the sample collected prior to dosing as baseline.

\section{Tandem mass spectrometric identification of peptides}

Employing collision-induced dissociation and the LIFT technology of the UltrafleXtreme, tandem MS (MS/MS) spectra of selected APLP1 peptides were acquired. These were processed and annotated in the BioTools software v3.2 (Bruker Daltonics $\mathrm{GmbH}$ ) by employing an in-house Mascot Deamon server (v2.3.2; Matrix Science Ltd. London, UK) search against an in-house designated APLP1 [UniProtKB:P51693] database. The parameters for searching the database were set to singly charged ions, variable methionine oxidation, a mass tolerance of $200 \mathrm{ppm}, \mathrm{MS} / \mathrm{MS}$ tolerance of $0.5 \mathrm{Da}$ and a MALDI-TOF/ TOF instrumentation. MS and MS/MS spectra were also acquired from human CSF using the same sample preparation methodology as described above. CSF samples were supplied by clinical routine at the Clinical Neurochemistry Laboratory, The Sahlgrenska University Hospital, Mölndal, Sweden, in accordance with ethical approval from the regional ethics committee at the University of Gothenburg. The samples were de-identified by pooling.

\section{Statistical analysis}

Statistical analysis was performed using GraphPad PRISM v6.04 (GraphPad Software, Inc., San Diego, USA) comparing the fold-change within each of the doses for the indicated peptides with Friedman test and employing Dunn's test for correction of multiple comparisons. 
Significant results were considered differences with a calculated $p$-value of $<0.05$.

\section{Results}

Identification of APLP1 peptides in CSF

By combing the selectivity of the in-house mouse monoclonal antibody, AP1, and MS, we here for the first time show that several APLP1 derived peptides may be used as biomarkers for target engagement of the GSM E2012 in vivo.

The amino acid sequence for APLP1 for Canis familiaris and Homo sapiens has a $100 \%$ homology [UniprotKB:J9JHP8 versus UniprotKB:P51693]. In total, 14 APLP1 peptides were identified in human CSF and 12 in dog CSF of which nine were confirmed by MS/MS (see Fig. 1 and Tables 1 and 2 for all identified peptides). All confirmed peptides started with the aspartic acid found at amino acid 568 of APLP1 [UniprotKB:P51693] and included peptides ranging between APLP1 $\beta 13$ up to APLP1 $\beta 28$. An additional peak that had the mass of the peptide plus $16 \mathrm{Da}$, corresponding to oxidation of methionine at position 21, was also observed for several of the APLP peptides (Fig. 1). Fragment ion mass spectra used for the identification of APLP1 1317 and APLP1 $\beta 28$ are shown in Fig. 2a and b, respectively.

\section{Modulation of APLP1 processing by E2012 in dogs}

In total, seven APLP1 peptides were reproducibly detected in all dog CSF samples (APLP1 $1 \beta 17,1 \beta 18,1 \beta 21$, $1 \beta 22,1 \beta 25,1 \beta 27$ and $1 \beta 28)$ and their response to treatment with E2012 was further investigated. See Fig. 3 for representative mass spectra from a dog treated with $80 \mathrm{mg} / \mathrm{kg}$ of the GSM E2012.

Four hours after administration of the GSM E2012 $(80 \mathrm{mg} / \mathrm{kg})$, we found higher levels of APLP1ß17 ( $p=$ $0.027)$ and APLP1 $\beta 18(p=0.016)$ compared to 8 hours

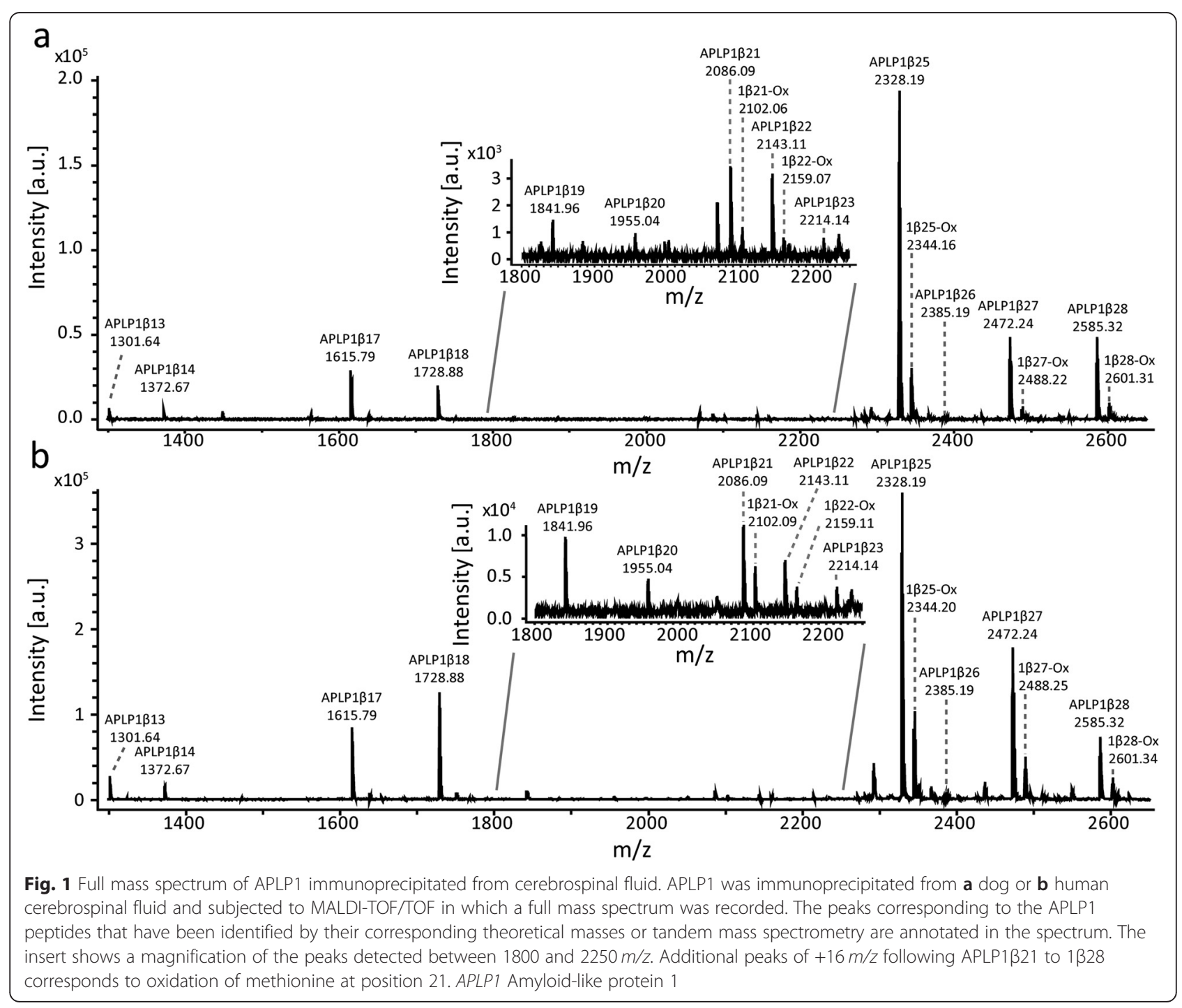


Table 1 APLP1 precursor ion identification in full mass spectrum

\begin{tabular}{|c|c|c|c|c|c|c|}
\hline Sequence & $\begin{array}{l}\text { Theoretical } \\
\text { mass (Da) }\end{array}$ & $\begin{array}{l}\text { Observed mass } \\
(\mathrm{Da}) \text { dogs }\end{array}$ & ppm dogs & $\begin{array}{l}\text { Observed mass } \\
\text { (Da) human }\end{array}$ & ppm human & Annotation \\
\hline DELAPAGTGVSRE & 1300.63 & 1300.60 & -172 & 1300.63 & 39 & APLP1ß13 \\
\hline DELAPAGTGVSREA & 1371.66 & 1371.65 & -114 & 1371.67 & 20 & APLP1ß14 \\
\hline DELAPAGTGVSREAVSG & 1614.78 & 1614.78 & -8.5 & 1614.78 & -0.058 & APLP1ß17 \\
\hline DELAPAGTGVSREAVSGL & 1727.87 & 1727.87 & 13 & 1727.87 & 0.12 & APLP1ß18 \\
\hline DELAPAGTGVSREAVSGLL & 1840.95 & 1840.96 & 12 & 1840.95 & -8.2 & APLP1ß19 \\
\hline DELAPAGTGVSREAVSGLLI & 1954.04 & 1954.04 & 8.5 & 1954.04 & -8.5 & APLP1 $\beta 20$ \\
\hline DELAPAGTGVSREAVSGLLIM & 2085.08 & 2085.08 & -2.4 & 2085.08 & 1.1 & APLP1 $\beta 21$ \\
\hline DELAPAGTGVSREAVSGLLIMG & 2142.10 & 2142.10 & -7.6 & 2142.10 & -0.46 & APLP1 $1 \beta 22$ \\
\hline DELAPAGTGVSREAVSGLLIMGA & 2213.14 & - & - & 2213.13 & -13 & APLP1 $\beta 23$ \\
\hline DELAPAGTGVSREAVSGLLIMGAG & 2270.16 & - & - & 2270.16 & 8.5 & APLP1 324 \\
\hline DELAPAGTGVSREAVSGLLIMGAGG & 2327.18 & 2327.18 & 3.3 & 2327.18 & 1.0 & APLP1ß25 \\
\hline DELAPAGTGVSREAVSGLLIMGAGGG & 2384.20 & 2384.19 & -33 & 2384.19 & -65 & APLP1 $\beta 26$ \\
\hline DELAPAGTGVSREAVSGLLIMGAGGGS & 2471.23 & 2471.23 & -0.53 & 2471.23 & -0.91 & APLP1 $\beta 27$ \\
\hline DELAPAGTGVSREAVSGLLIMGAGGGSL & 2584.32 & 2584.32 & 0.72 & 2584.32 & 0.31 & APLP1 $\beta 28$ \\
\hline
\end{tabular}

Full mass spectra of amyloid-like protein 1 (APLP1) immunoprecipitated from dog and human cerebrospinal fluid were acquired by MALDI-TOF/TOF. The Table shows the amino acid sequences, the observed masses in Da in dogs and human and their deviation from the theoretical peptide mass in ppm for the peptides identified

post-treatment. The increases reverted to baseline levels at 8 hours post-treatment and remained at baseline levels 24 hours post-treatment (Fig. 4a and b). No significant differences were observed for the two peptides after the $20 \mathrm{mg} / \mathrm{kg}$ dose (Fig. $4 \mathrm{a}$ and b). After administration of $80 \mathrm{mg} / \mathrm{kg}$, the levels of APLP1 $\beta 25$ were significantly decreased both at 4 hours $(p=0.0032)$ and 8 hours ( $p=0.0032)$ post-treatment (Fig. 4e). The $20 \mathrm{mg} / \mathrm{kg}$ dose showed a similar trend without reaching statistical significance (Fig. 4e). APLP1 328 showed a dose-dependent increase at 8 hours post-treatment which was significant for $80 \mathrm{mg} / \mathrm{kg}(p=0.0032)$ but not $20 \mathrm{mg} / \mathrm{kg}$ (Fig. $4 \mathrm{~g}$ ).

Table 2 Tandem mass spectrometric identification of APLP1 peptides

\begin{tabular}{|c|c|c|c|c|c|}
\hline Peptide & Observed $\mathrm{m} / \mathrm{z}$ & ppm & Ion score & Expect & $\mathrm{a} / \mathrm{b} / \mathrm{y}$ ions \\
\hline APLP1及14 & 1372.71 & 30.4 & 48 & $1.6 \times 10^{-5}$ & $-/ 4 / 6$ \\
\hline APLP1ß17 & 1615.83 & 23.7 & 79 & $1.3 \times 10^{-8}$ & $4 / 6 / 11$ \\
\hline APLP1 $\beta 18$ & 1728.91 & 21.9 & 65 & $3.0 \times 10^{-7}$ & $-/ 8 / 10$ \\
\hline APLP1ß19 & 1842.06 & 56.7 & 18 & $1.7 \times 10^{-2}$ & $-/ 5 / 4$ \\
\hline APLP1 $\beta 21$ & 2086.19 & 48.1 & 24 & $3.9 \times 10^{-3}$ & $-/ 6 /-$ \\
\hline APLP1 $\beta 23$ & 2214.14 & -2.91 & 15 & $3.3 \times 10^{-2}$ & $-/ 4 /-$ \\
\hline APLP1 $\beta 25$ & 2328.51 & 138 & 79 & $1.3 \times 10^{-8}$ & $7 / 6 / 11$ \\
\hline APLP1 $\beta 27$ & 2472.31 & 27.8 & 100 & $9.4 \times 10^{-11}$ & $9 / 5 / 9$ \\
\hline APLP1 $\beta 28$ & 2585.40 & 28.3 & 93 & $5.3 \times 10^{-10}$ & $9 / 11 / 10$ \\
\hline
\end{tabular}

The Table shows the peptides that were identified by tandem mass spectrometry. The acquired fragment mass spectra were used for searching an in-house Mascot Deamon server containing a designated amyloid-like protein 1 (APLP1) database. Also shown are the observed masses and the deviation from the theoretical masses in ppm, as well as identification statistics given as the Mascot lon Score and Expect value. The number of identified $a, b$ and $y$ ions are also indicated
However, the increase at 8 hours was significant relative to 24 hours post-treatment for both doses $(p=0.0032$ and $p=0.047$ for $80 \mathrm{mg} / \mathrm{kg}$ and $20 \mathrm{mg} / \mathrm{kg}$, respectively; Fig. 4g).

APLP1 121 and APLP1 $\beta 22$ did not show any significant deviations from baseline for either of the two doses (Fig. 4c and d). The level of APLP1ß27 showed a trend towards decreased levels in a dose-dependent manner in response to treatment but it did not reach statistical significance for either of the doses (Fig. 4f).

\section{Discussion}

In the present study, we show that APLP1 in CSF is present as a variety of short peptides. For the first time we also demonstrate that the levels of several CSF APLP1 peptides are markedly affected in response to treatment with the GSM E2012 suggesting that APLP1-derived peptides may be used as biomarkers to prove target engagement for this type of treatments. To our knowledge there are no studies of the effect of $\gamma$-secretase modulators on APLP1 processing in vivo to date.

Previously, using an explorative proteomics approach, we identified eight endogenous APLP1 peptides in human CSF including APLP1 $\beta 17,1 \beta 18,1 \beta 25$ and $1 \beta 27$ [35]. By employing the targeted approach described herein we have identified and confirmed the presence of the previously identified peptides in CSF [28, 35] and have now extended the list of identified endogenous APLP1 peptides. A previous report showed an increase of APLP1 128 relative to the total amount of APLP1 peptides in CSF from AD subjects [28] while we recently showed that the levels of APLP1 $\beta 25,1 \beta 27$ and $1 \beta 28$ in 


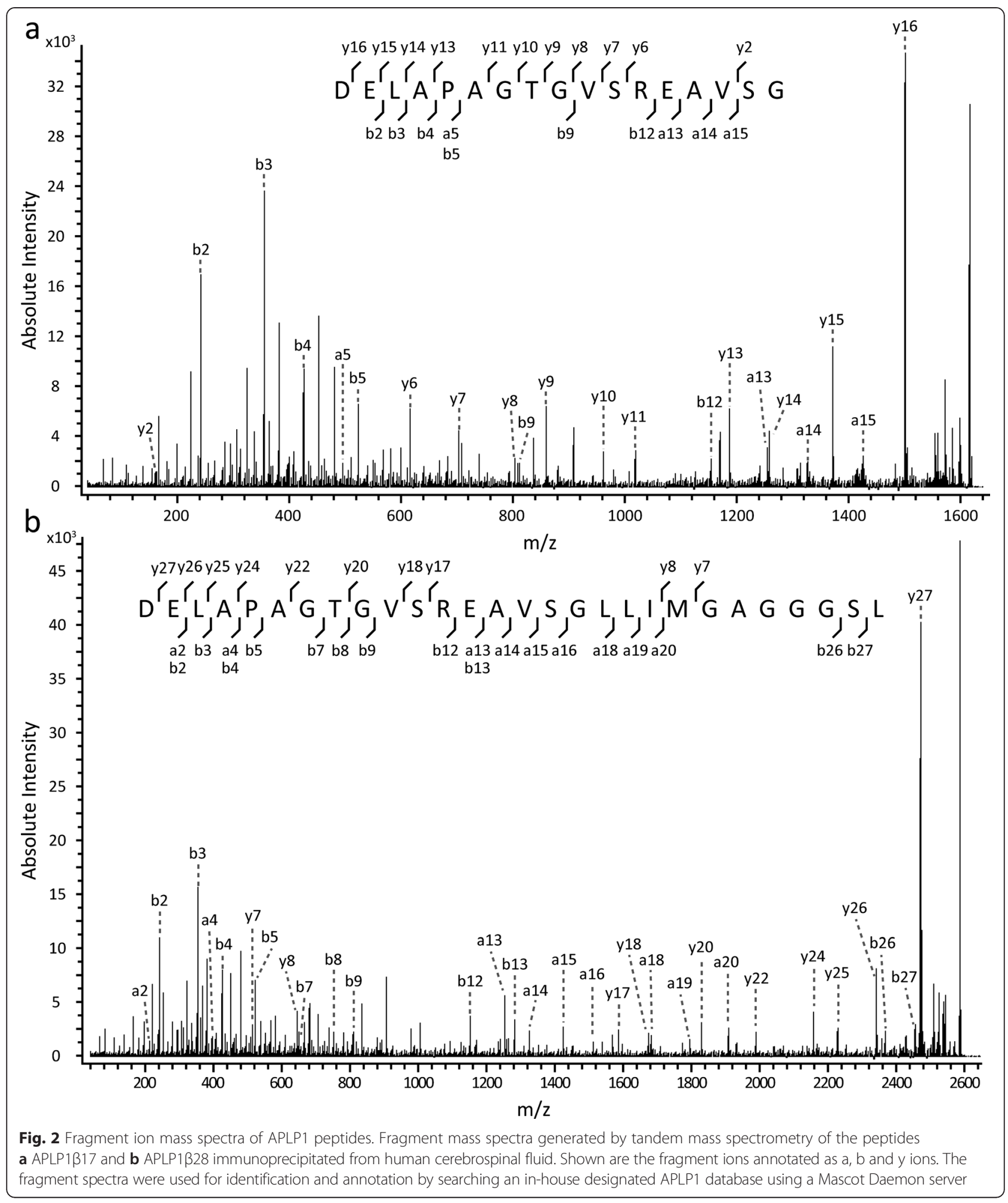

CSF from Down's syndrome patients are decreased as compared to healthy controls [36]. However, whether CSF APLP1 $\beta 28$ can be used as an AD or Down's syndrome biomarker needs to be investigated in large clinical studies.
Of the 12 identified APLP1 peptides in dog CSF, we show that several are affected in response to treatment with the GSM E2012 and that some peptides are affected in a dose-dependent manner as the effect was more pronounced with the higher dose $(80 \mathrm{mg} / \mathrm{kg})$. We found 


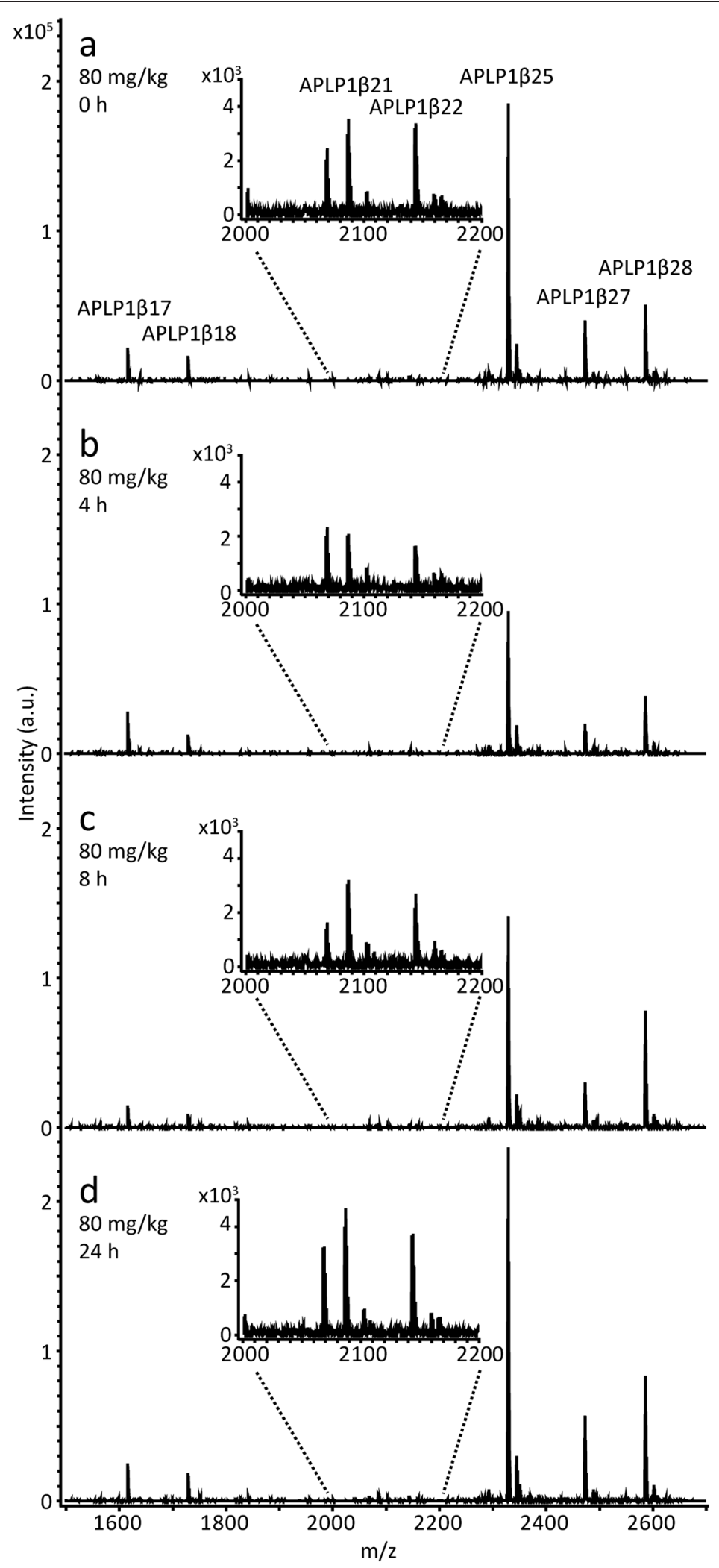

Fig. 3 Full mass spectrum of $80 \mathrm{mg} / \mathrm{kg}$ Y-secretase modulation effect in dogs. Full mass spectra of APLP1 were acquired by hybrid immuno-affinity MALDI-TOF/TOF mass spectrometry. The spectra show the relative changes of the APLP1 peptides in cerebrospinal fluid collected from a dog a prior to dosing with $80 \mathrm{mg} / \mathrm{kg}$ of the $\gamma$-secretase modulator E2012 and subsequently b 4, c 8 and $\mathbf{d} 24$ hours after dosing. APLP1 Amyloid-like protein 1 
increased relative levels of APLP1 $\beta 17,1 \beta 18$ and $1 \beta 28$ in response to treatment accompanied by decreased relative levels of APLP1 1325 and $1 \beta 27$. The changes in the levels for all of the peptides seem to revert towards baseline levels over time. For APLP1 $\beta 21$ and $1 \beta 22$ we found no significant difference. These findings suggest that the modulation of the APLP1 processing affects the production over the range of peptides present, not only a single peptide or exclusively shorter or longer peptides. Furthermore, the transmembrane region of APLP1 ranges from position 581-603. Thus all identified APLP1 peptides, except APLP1 $\beta 13$, are located within this region and are accessible for $\gamma$-secretase processing.
Previously we have shown that the CSF levels of $A \beta_{37}$ increases and $A \beta_{42}$ decreases in dogs treated with the GSM E2012 [21]. Here we show in the very same material that the levels of several APLP1 peptides are affected in response to E2012 treatment. Thus investigating the level of APLP1 peptides in GSM treatment trials may be highly informative and possibly increase our understanding of the mechanistics and dynamics of APLP processing in the disease.

One limitation with the current study is that the epitope of the APLP1 antibody used (AP1) has not been determined. However MS analysis, including MS/MS, confirms that the peptides studied in the present study

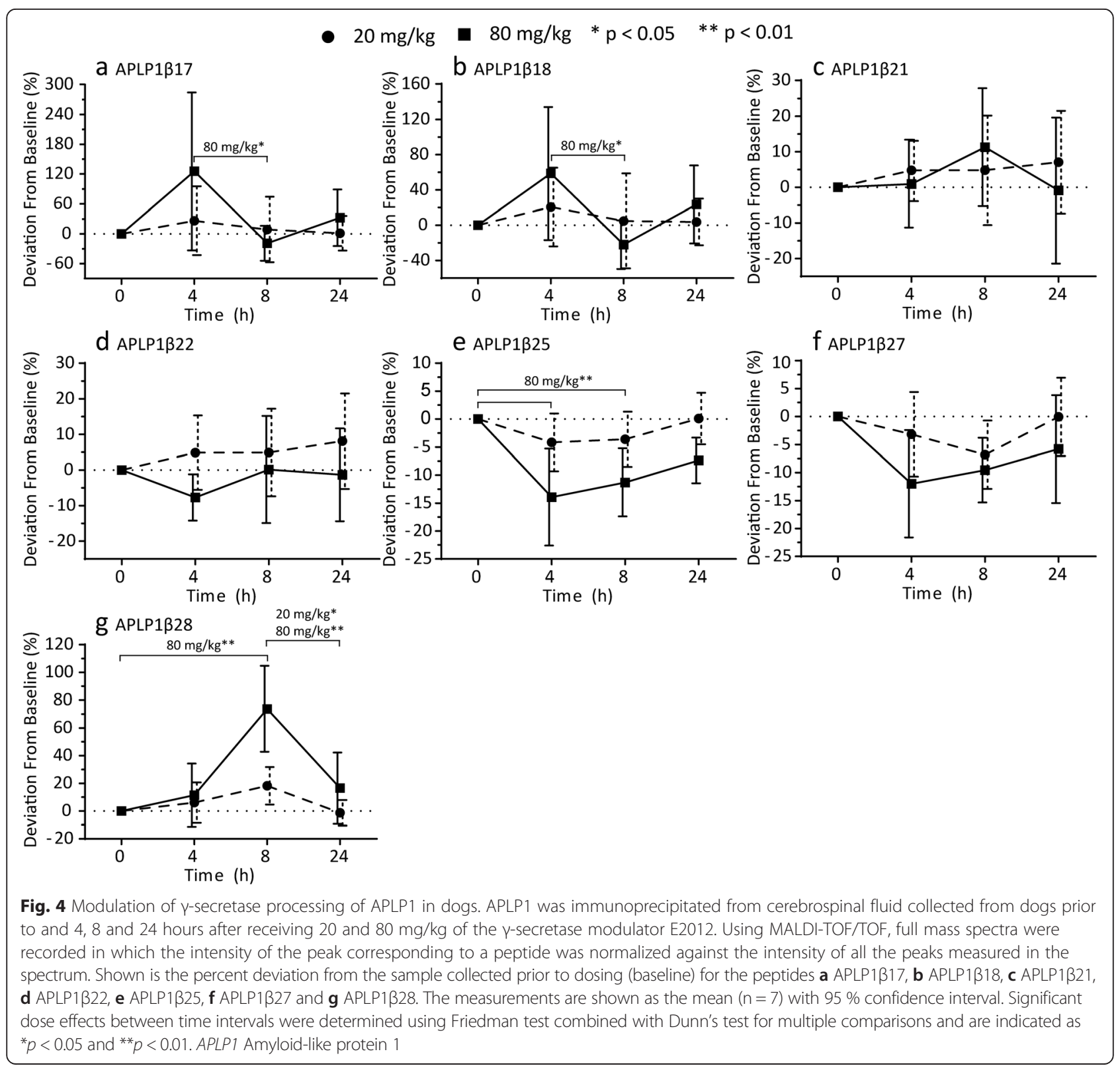


indeed are APLP1 derived. It should also be noted that the ratio between the different endogenous APLP1 peptides detected cannot be interpreted as a direct reflection of their absolute abundance in the CSF. This is because the ionization efficiency might be different for the different peptides. Phase I trials in man are needed to further study the potential of CSF APLP1 peptides to verify target engagement of GSM drug candidates as well as longterm clinical trials to examine if these biomarkers also may predict a beneficial clinical treatment effect.

With GSMs, one of the benefits is to avoid the potential inhibition of processing of non-intended substrates such as Notch $[16,17]$ which has been one of the main concerns when using $\gamma$-secretase inhibitors. However, GSMs have also shown an effect on Notch processing but in respect to cleavage site preference and not inhibition [37]. How GSMs affect the processing of the substrates is to a large extent unclear. It is likely dependent on the particular modulator used and the target with which it interacts [22]. First generation GSMs have been hypothesized to interact with the substrate, the secretase, or both [22], and it has been further speculated that, in the instance of modulators targeting the APP and $A \beta$ sequences, this might affect the processing by adjusting the position of the amino acid sequence in relation to the membrane [38]. Second-generation GSMs, to which E2012 belongs, have been shown rather to interact with the subunits of $\gamma$-secretase [22]. Specifically, E2012 has been indicated to bind to the N-terminal fragment of PS1 in a competitive manner $[39,40]$.

\section{Conclusions}

We have identified a number of APLP1 peptides in human and dog CSF. Furthermore we have shown that $\gamma$-secretase modulation, using the GSM E2012, affects APLP1 proteolytic processing in vivo and that this is reflected in the relative levels of a number of APLP1 peptides. The soluble nature of the APLP1 peptides $[24,28]$ and the fact that APLP1 is a $\gamma$-secretase substrate, as indicated herein and shown elsewhere [28-30], suggests that secreted APLP1 fragments may be informative when investigating $\gamma$-secretase cleavage products in AD. Our findings show that APLP1 peptides can be used as in vivo biomarkers for E2012 treatment, which may be translated to other second-generation GSMs.

\section{Abbreviations}

Aß: Amyloid $\beta$; AD: Alzheimer's disease; APLP1: Amyloid-like protein 1; APP: Amyloid precursor protein; CSF: Cerebrospinal fluid; GSM: $\gamma$-Secretase modulator; MALDI-TOF/TOF: Matrix-assisted laser desorption ionization time-of-flight/time-of-flight; MS: Mass spectrometry; MS/MS: Tandem mass spectrometry; PS: Presenilin.

\section{Competing interests}

$\mathrm{HB}$ and $\mathrm{MM}$ are employed by Janssen. SS, KKAA, HZ, KB and EP declare that they have no competing interests.

\section{Authors' contributions}

SS performed the hybrid immuno-affinity mass spectrometry experiments, statistical analyses and drafted the manuscript. HB designed the study, facilitated the animal treatment regime and CSF collection and revised the draft for important intellectual content. KKAA produced the monoclonal antibody and revised the draft for important intellectual content. MM designed the study and revised the draft for important intellectual content. $\mathrm{HZ}$ designed the study and revised the draft for important intellectual content. KB designed the study, designed the production of anti-APLP antibodies and revised the draft for important intellectual content. EP designed the study and drafted the manuscript. All authors interpreted the data. All authors agree with the presented findings and read and approved the final manuscript.

\section{Acknowledgements}

This study was supported by grants from the Research Council, Sweden (grant \#14002), Hjärnfonden, and the Torsten Söderberg Foundation at the Royal Academy of Sciences.

\section{Author details}

${ }^{1}$ Institute of Neuroscience and Physiology, Department of Psychiatry and Neurochemistry, The Sahlgrenska Academy at the University of Gothenburg, Sahlgrenska University Hospital, Mölndal S-431 80, Sweden. ²Janssen Research and Development, Beerse, Belgium. ${ }^{3} \mathrm{UCL}$ Institute of Neurology, University College London, London, UK.

Received: 21 August 2015 Accepted: 28 October 2015

Published online: 22 December 2015

\section{References}

1. Mayeux R, Stern Y. Epidemiology of Alzheimer disease. Cold Spring Harb Perspect Med. 2012;2:1-18. doi:10.1101/cshperspect.a006239.

2. Masters $C L$, Simms G, Weinman NA, Multhaup G, McDonald BL, Beyreuther K. Amyloid plaque core protein in Alzheimer disease and Down syndrome. Proc Natl Acad Sci U S A. 1985;82:4245-9.

3. Grundke-labal I, Iqbal K, Tung YC, Quinlan M, Wisniewski HM, Binder LI. Abnormal phosphorylation of the microtubule-associated protein tau (tau) in Alzheimer cytoskeletal pathology. Proc Natl Acad Sci U S A. 1986;83:4913-7.

4. Hardy JA, Higgins GA. Alzheimer's disease: the amyloid cascade hypothesis Science. 1992;256:184-5.

5. De Strooper B. Lessons from a failed gamma-secretase Alzheimer trial. Cell. 2014;159:721-6. doi:10.1016/j.cell.2014.10.016.

6. Mangialasche F, Solomon A, Winblad B, Mecocci P, Kivipelto M. Alzheimer's disease: clinical trials and drug development. Lancet Neurol. 2010;9:702-16. http://dx.doi.org/10.1016/S1474-4422(10)70119-8 (accessed 2015-11-09).

7. Citron M. Alzheimer's disease: strategies for disease modification. Nat Rev Drug Discov. 2010;9:387-98.

8. Kuhn PH, Wang H, Dislich B, Colombo A, Zeitschel U, Ellwart JW, et al. ADAM10 is the physiologically relevant, constitutive alpha-secretase of the amyloid precursor protein in primary neurons. EMBO J. 2010;29:3020-32. doi:10.1038/emboj.2010.167.

9. Vassar R, Bennett BD, Babu-Khan S, Kahn S, Mendiaz EA, Denis P, et al. Beta-secretase cleavage of Alzheimer's amyloid precursor protein by the transmembrane aspartic protease BACE. Science. 1999;286:735-41.

10. Kimberly WT, LaVoie MJ, Ostaszewski BL, Ye W, Wolfe MS, Selkoe DJ. Gamma-secretase is a membrane protein complex comprised of presenilin, nicastrin, Aph-1, and Pen-2. Proc Natl Acad Sci U S A. 2003;100:6382-7. doi:10.1073/pnas.1037392100.

11. De Strooper B, Saftig P, Craessaerts K, Vanderstichele H, Guhde G, Annaert W, et al. Deficiency of presenilin-1 inhibits the normal cleavage of amyloid precursor protein. Nature. 1998;391:387-90. doi:10.1038/34910.

12. Esch FS, Keim PS, Beattie EC, Blacher RW, Culwell AR, Oltersdorf T, et al. Cleavage of amyloid beta peptide during constitutive processing of its precursor. Science. 1990;248:1122-4.

13. Doody RS, Raman R, Farlow M, Iwatsubo T, Vellas B, Joffe $S$, et al. A phase 3 trial of semagacestat for treatment of Alzheimer's disease. N Engl J Med. 2013;369:341-50. doi:10.1056/NEJMoa1210951.

14. Coric V, van Dyck CH, Salloway S, Andreasen N, Brody M, Richter RW, et al. Safety and tolerability of the gamma-secretase inhibitor avagacestat in a 
phase 2 study of mild to moderate Alzheimer disease. Arch Neurol. 2012;69:1430-40. doi:10.1001/archneurol.2012.2194.

15. McCarthy JV, Twomey C, Wujek P. Presenilin-dependent regulated intramembrane proteolysis and $\gamma$-secretase activity. Cell Mol Life Sci. 2009;66:1534-55. doi:10.1007/s00018-009-8435-9.

16. De Strooper B, Annaert W, Cupers P, Saftig P, Craessaerts K, Mumm JS, et al. A presenilin-1-dependent gamma-secretase-like protease mediates release of Notch intracellular domain. Nature. 1999;398:518-22. doi:10.1038/19083.

17. Struhl G, Greenwald I. Presenilin is required for activity and nuclear access of Notch in Drosophila. Nature. 1999;398:522-5. doi:10.1038/19091.

18. Barthet $\mathrm{G}$, Georgakopoulos A, Robakis NK. Cellular mechanisms of gamma-secretase substrate selection, processing and toxicity. Prog Neurobiol. 2012;98:166-75. doi:10.1016/j.pneurobio.2012.05.006.

19. Ling IF, Golde TE, Galasko DR, Koo EH. Modulation of Abeta42 in vivo by gamma-secretase modulator in primates and humans. Alzheimers Res Ther. 2015;7:55. doi:10.1186/s13195-015-0137-y.

20. Portelius E, Appelkvist P, Strömberg K, Höglund K. Characterization of the effect of a novel $Y$-secretase modulator on $A B$ : a clinically translatable model. Curr Pharm Des. 2014;20:2484-90.

21. Portelius E, Van Broeck B, Andreasson U, Gustavsson MK, Mercken M, Zetterberg $\mathrm{H}$, et al. Acute effect on the Abeta isoform pattern in CSF in response to gamma-secretase modulator and inhibitor treatment in dogs. J Alzheimers Dis. 2010;21:1005-12. doi:10.3233/JAD-2010-100573.

22. Crump CJ, Johnson DS, Li YM. Development and mechanism of gamma-secretase modulators for Alzheimer's disease. Biochemistry. 2013;52:3197-216. doi:10.1021/bi400377p.

23. Jacobsen KT, Iverfeldt K. Amyloid precursor protein and its homologues: a family of proteolysis-dependent receptors. Cell Mol Life Sci. 2009;66:2299-318. doi:10.1007/s00018-009-0020-8.

24. Minogue AM, Stubbs AK, Frigerio CS, Boland B, Fadeeva JV, Tang J, et al. gamma-secretase processing of APLP1 leads to the production of a p3-like peptide that does not aggregate and is not toxic to neurons. Brain Res. 2009;1262:89-99. doi:10.1016/..brainres.2009.01.008.

25. Baumkotter F, Wagner K, Eggert S, Wild K, Kins S. Structural aspects and physiological consequences of APP/APLP trans-dimerization. Exp Brain Res. 2012;217:389-95. doi:10.1007/s00221-011-2878-6.

26. Eggert S, Paliga K, Soba P, Evin G, Masters CL, Weidemann A, et al. The proteolytic processing of the amyloid precursor protein gene family members APLP-1 and APLP-2 involves alpha-, beta-, gamma-, and epsilon-like cleavages: modulation of APLP-1 processing by n-glycosylation. J Biol Chem. 2004;279:18146-56. doi:10.1074/jbc.M311601200.

27. Haass C, Schlossmacher MG, Hung AY, Vigo-Pelfrey C, Mellon A, Ostaszewski $\mathrm{BL}$, et al. Amyloid beta-peptide is produced by cultured cells during normal metabolism. Nature. 1992;359:322-5. doi:10.1038/359322a0.

28. Yanagida K, Okochi M, Tagami S, Nakayama T, Kodama TS, Nishitomi K, et al. The 28-amino acid form of an APLP1-derived Abeta-like peptide is a surrogate marker for Abeta42 production in the central nervous system. EMBO Mol Med. 2009;1:223-35. doi:10.1002/emmm.200900026.

29. Naruse S, Thinakaran G, Luo JJ, Kusiak JW, Tomita T, Iwatsubo T, et al. Effects of PS1 deficiency on membrane protein trafficking in neurons. Neuron. 1998;21:1213-21.

30. Walsh DM, Fadeeva JV, LaVoie MJ, Paliga K, Eggert S, Kimberly WT, et al. gamma-Secretase cleavage and binding to FE65 regulate the nuclear translocation of the intracellular C-terminal domain (ICD) of the APP family of proteins. Biochemistry. 2003;42:6664-73. doi:10.1021/bi027375c

31. Li Q, Sudhof TC. Cleavage of amyloid-beta precursor protein and amyloid-beta precursor-like protein by BACE 1. J Biol Chem. 2004;279:10542-50. doi:10.1074/jbc.M310001200.

32. Tagami S, Okochi M, Yanagida K, Kodama T, Arai T, Kuwano R, et al. Relative ratio and level of amyloid-beta 42 surrogate in cerebrospinal fluid of familial Alzheimer disease patients with presenilin 1 mutations. Neurodegener Dis. 2014;13:166-70. doi:10.1159/000355258.

33. Kimura T, Kawano K, Doi E, Kitazawa N, Shin K, Miyagawa T, et al. inventors; Cinnamide compound patent PCT Int. Appl. WO2005115990(A1). 2005.

34. Wilsson-Rahmberg M, Olovson SG, Forshult E. Method for long-term cerebrospinal fluid collection in the conscious dog. J Invest Surg. 1998;11:207-14.

35. Holtta M, Zetterberg H, Mirgorodskaya E, Mattsson N, Blennow K, Gobom J. Peptidome analysis of cerebrospinal fluid by LC-MALDI MS. PLoS One. 2012;7:e42555. doi:10.1371/journal.pone.0042555.
36. Portelius $E$, Holtta $M$, Soininen $H$, Bjerke $M$, Zetterberg $H$, Westerlund $A$, et al. Altered cerebrospinal fluid levels of amyloid beta and amyloid precursor-like protein 1 peptides in Down's syndrome. Neuromolecular Med. 2014;16:510-6. doi:10.1007/s12017-014-8302-1.

37. Wanngren J, Ottervald J, Parpal S, Portelius E, Stromberg K, Borgegard T, et al. Second generation gamma-secretase modulators exhibit different modulation of Notch beta and Abeta production. J Biol Chem. 2012;287:32640-50. doi:10.1074/jbc.M112.376541.

38. Kukar TL, Ladd TB, Bann MA, Fraering PC, Narlawar R, Maharvi GM, et al. Substrate-targeting gamma-secretase modulators. Nature. 2008;453:925-9. doi:10.1038/nature07055.

39. Ebke A, Luebbers T, Fukumori A, Shirotani K, Haass C, Baumann K, et al. Novel $\gamma$-secretase enzyme modulators directly target presenilin protein. J Biol Chem. 2011;286:37181-6. doi:10.1074/jbc.C111.276972.

40. Pozdnyakov N, Murrey HE, Crump CJ, Pettersson M, Ballard TE, Am Ende CW, et al. Gamma-secretase modulator (GSM) photoaffinity probes reveal distinct allosteric binding sites on presenilin. J Biol Chem. 2013;288:9710-20. doi:10.1074/jbc.M112.398602.

\section{Submit your next manuscript to BioMed Central and take full advantage of:}

- Convenient online submission

- Thorough peer review

- No space constraints or color figure charges

- Immediate publication on acceptance

- Inclusion in PubMed, CAS, Scopus and Google Scholar

- Research which is freely available for redistribution

Submit your manuscript at www.biomedcentral.com/submit 